\title{
A Hippocampal NR2B Deficit Can Mimic Age-Related Changes in Long-Term Potentiation and Spatial Learning in the Fischer 344 Rat
}

\author{
Daniel A. Clayton, ${ }^{1,2}$ Michael H. Mesches, ${ }^{2,3,4}$ Enriquez Alvarez,, ${ }^{1,2}$ Paula C. Bickford, ${ }^{5,6}$ and \\ Michael D. Browning 2,3 \\ ${ }^{1}$ Medical Scientist Training Program, ${ }^{2}$ Neuroscience Program, and ${ }^{3}$ Department of Pharmacology, University of Colorado \\ Health Sciences Center, Denver, Colorado, 80262, ${ }^{4}$ Veterans Affairs Medical Center, Denver, Colorado 80220, 5 James A. \\ Haley Veterans Affairs Medical Center, Tampa, Florida 33612, and ${ }^{6}$ Center for Aging and Brain Repair, Department of \\ Neurosurgery, University of South Florida, Tampa, Florida 33169
}

Aged rats are known to have deficits in spatial learning behavior in the Morris water maze. We have found that aged rats also have deficits in NR2B protein expression and that the protein expression deficit is correlated with their performance in the Morris water maze. To test whether this NR2B deficit was sufficient to account for the behavioral deficit, we used antisense oligonucleotides to specifically knock down NR2B subunit expression in the hippocampus of young rats. NR2B anti- sense treatment diminished NMDA receptor responses, abolished NMDA-dependent long-term potentiation (LTP), and impaired spatial learning. These data demonstrate the important role of NR2B in LTP and learning and memory and suggest a role for reduced NR2B expression in age-related cognitive decline.

Key words: NMDA; NR2B; aging; LTP; learning; antisense
It has been known for some time that aged rats have deficits in spatial learning tasks (Barnes, 1979; Barnes et al., 1980; deToledo-Morrell et al., 1988; Ward et al., 1999a,b) and in longterm potentiation (LTP), a form of synaptic plasticity, which displays many of the characteristics thought to be required for a molecular mechanism of memory formation (Landfield and Lynch, 1977; Landfield et al., 1978; deToledo-Morrell et al., 1988; Gallagher et al., 1993; Moore et al., 1993; Shankar et al., 1998; Ward et al., 1999a,b).

LTP can be segregated semantically and mechanistically into at least two phases: the early phase of LTP (usually described $<1 \mathrm{hr}$ after stimulation), which does not require protein synthesis and gene transcription; and the late phase of LTP (usually described as $>3 \mathrm{hr}$ after stimulation), which does require protein synthesis and gene transcription. Several studies of aging and LTP have failed to demonstrate any age-related deficits using suprathreshold stimulation paradigms, such as high-frequency stimulation (HFS; one or more trains of $1 \mathrm{sec}$ of $100 \mathrm{~Hz}$ stimulation) in the early phase of LTP; however, age-related deficits have commonly been reported in the late phase (Moore et al., 1993; Lanahan et al., 1997; Bach et al., 1999; Costenla et al., 1999; Eckles-Smith et al., 2000). Perithreshold stimulation protocols (such as theta burst and primed burst stimulation) have revealed age-related deficits in the induction of LTP (Moore et al., 1993; Lanahan et al., 1997; Costenla et al., 1999; Eckles-Smith et al., 2000). The NMDA receptor is known to be critical for most forms of LTP. Voltagegated calcium channels, however, might also contribute to LTP, and evidence exists to support an increasing role for voltagegated calcium channel use in aged animals alongside a decreasing role for NMDA receptors (Huber et al., 1995; Cavus and Teyler,

\footnotetext{
Received Jan. 7, 2002; revised Jan. 7, 2002; accepted Jan. 29, 2002.

Correspondence should be addressed to Michael D. Browning, 4209 East Ninth Avenue, Box C236, Denver, CO 80262. E-mail: Michael.Browning@uchsc.edu. Copyright (C) 2002 Society for Neuroscience $0270-6474 / 02 / 223628-10 \$ 15.00 / 0$
}

1996; Izumi and Zorumski, 1998; Shankar et al., 1998; Morgan and Teyler, 1999).

We and others have reported age-related decreases in the expression of certain subunits of the NMDA receptor and in the function of the NMDA receptor in the CA1 subfield of the hippocampus (Granger et al., 1996; Barnes et al., 1997; EcklesSmith et al., 2000; Kuehl-Kovarik et al., 2000; Sonntag et al., 2000; Clayton and Browning, 2001). Differential assembly of the subunits of the NMDA receptor is thought to result in channels with different functional properties (Meguro et al., 1992; Zhong et al., 1995; Audinat et al., 1996; Brimecombe et al., 1997; Flint et al., 1997; Vallano, 1998; Rumbaugh and Vicini, 1999; Tovar and Westbrook, 1999). In particular, the NR2B subunit has been suggested to have a critical role in spatial learning and LTP, as evidenced by NR2B knock-out and overexpressing mice (Sprengel et al., 1998; Tang et al., 1999; Tovar et al., 2000).

In the present report, we examine the connection between deficits in NMDA receptor subunit expression and deficits in LTP and spatial learning behavior both as they occur together in aged animals and in an experimental system in which we used antisense oligonucleotides to specifically decrease the expression of the NR2B subunit of the NMDA receptor.

\section{MATERIALS AND METHODS}

Animals. Male Fischer 344 rats were used for all experiments in these studies and were obtained from the colony of the National Institute on Aging at Harlan Biosciences. An age spectrum of animals was selected ranging from 2 to 24 months of age; ages are given in individual experiments.

Semiquantitative Western blotting. Protein concentrations were determined for each sample using a modified BCA assay (Pierce, Rockford, IL). Duplicate samples were electrophoresed on 7.5\% SDS-PAGE gels by a standard procedure. A standard hippocampal homogenate dilution series was also run on each gel to allow for standardized quantitation. Gels were transferred to polyvinylidene difluoride membranes (NEN, Boston, MA) and blocked with 5\% milk. Primary antibodies were incubated with the blot for $16 \mathrm{hr}$ in $1 \%$ milk. Secondary antibodies were incubated for $1 \mathrm{hr}$ in $1 \%$ milk. The blots were developed using Super- 
Signal chemiluminescent reagent (Pierce) and analyzed using an AlphaImager (Alpha-Innotech). Quantitation was performed using AlphaEase software (Alpha-Innotech) and Excel (Microsoft, Redmond, WA). The NR1 antibody was obtained from a commercial source (PharMingen, San Diego, CA) and has been previously characterized. The primary antibodies from our laboratory (NR2A, NR2B, and synapsin) have been previously characterized in terms of specificity and suitability for quantitative Western blot analysis (Nayak et al., 1998). The Glu receptor 1 (GluR1) and GluR2 antibodies (Chemicon, Temecula, CA) have been previously characterized as well (Zhao et al., 1998).

Behavioral analyses. For correlation studies, animals were trained in a Morris water maze (1.5 m diameter, 10 -cm-diameter platform submerged $1 \mathrm{~cm}$ below the surface of $27^{\circ} \mathrm{C}$ water) for three trials per day for $10 \mathrm{~d}$. The maze was divided into four imaginary quadrants, and the platform was placed in the middle of one quadrant for all trials. Animals were started from one of three start points equidistant from the platform in a pseudorandom manner. Every other day, the third trial was a probe trial (platform retracted to the bottom of the maze for the first $30 \mathrm{sec}$ of the trial). A trial consisted of an animal having $60 \mathrm{sec}$ of free swim time in the maze, during which the amount of time, distance, and cumulative distance from the platform were measured. At the end of $60 \mathrm{sec}$, if the animal had not found the platform, the animal was gently guided to the platform. Animals remained on the platform for $30 \mathrm{sec}$ between trials. Data were collected either with Chromotrak (San Diego Instruments, San Diego, CA) or WaterMaze (Actimetrics, Evanston, IL) data acquisition programs using a video camera connected to a personal computer. The tracking units used are not in SI units but instead are relative to the number of pixels in the field of view of the camera. Under the conditions in which the systems were assembled, these tracking units are equal to $0.63 \mathrm{~cm}$. All trials were monitored to ensure proper animal identification and tracking (all animals were confirmed to be in the water maze during the entire period of the experiment).

For antisense behavioral analysis, animals were trained in the Morris water maze for four trials per day for $5 \mathrm{~d}$. Training was started on the day after injection of antisense based on preliminary data that had determined that the greatest difference in performance occurred between days 1 and 2; this thus superimposed the time courses of the greatest depression in NR2B expression with the greatest period of learning.

Antisense treatment. Because of the low stability of phosphodiesterlinked oligonucleotides and the high toxicity of completely phosphorothioated oligonucleotides, these oligonucleotides were synthesized with "end caps" in which the terminal three nucleotides at both the $5^{\prime}$ and $3^{\prime}$ ends are phosphorothioate-linked. The sequences of the antisense-NR2B and scrambled-NR2B oligonucleotides are as follows: antisense-NR2B, TGGGCTTCATCTTCAGCTAG; and scrambled-NR2B, GCTATGGTCTGTCAGCTTCA.

The scrambled oligonucleotide is of the same base composition as the antisense-NR2B oligonucleotide with the sequence scrambled such that no homology was found to known rat genes as of September 2000. Efforts were made to avoid the inclusion of features known to cause nonspecific effects such as $\mathrm{C}$ quartets and $\mathrm{CpG}$ motifs.

For the expression and electrophysiology experiments, animals were anesthetized with a ketamine-xylazine mixture $(100 \mathrm{mg} / \mathrm{kg}$ ketamine and $10 \mathrm{mg} / \mathrm{kg}$ xylazine) injected intramuscularly into the posterior thigh. The level of anesthesia was checked by squeezing both the anterior and posterior paws and by assessing the blink response to a cotton swab. The operative site was prepared by shaving the fur around the incision site followed by cleaning of the site with betadine and then alcohol. Incisions through the skin and underlying fascia were made using a number 10 scalpel blade, and the skull was exposed by blunt dissection to reveal both the bregma and the injection site. Holes were drilled through the skull using a burr drill at a location determined to lie above the desired intracranial site, and care was taken not to drill through the dura. The dura was punctured using a small-gauge needle. The cannulas were inserted stereotactically. Antisense oligonucleotides for the expression and LTP studies were injected as $10 \mathrm{nmol}$ in $1 \mu \mathrm{l}$ of PBS containing $0.2 \%$ India ink for visualization of the injection site postmortem over the course of $1 \mathrm{~min}$. India Ink staining showed little migration from the injection tract and was visible both grossly and under a dissection microscope. Coordinates used (relative to bregma) were anteroposterior, $-3.8 \mathrm{~mm}$; mediolateral, $\pm 2.0 \mathrm{~mm}$; and dorsoventral, along a $0.5 \mathrm{~mm}$ track from -2.25 to $-2.75 \mathrm{~mm}$ from the surface of the brain. Injection cannulas were left in place for an additional 2 min after injection and were "capped" with a $1 \mu \mathrm{l}$ air bubble by injecting the air as the cannula was slowly removed. Antisense-NR2B or scrambled-NR2B was injected into the left hippocampus, and vehicle (PBS and $0.2 \%$ India ink) was injected into the right hippocampus. After injection, the skull defects were sealed with bone wax, and the skin was approximated with the use of two to four 2-0 Vicryl sutures. Animals were allowed to recover from anesthesia under a heating lamp before returning to their cages. Localization of the injection tract was possible in $400 \mu \mathrm{m}$ hippocampal slices; four slices to either side of the injection tract were taken $(3.2 \mathrm{~mm}$ block of hippocampus) for expression studies. For electrophysiology, the two slices on either side of the injection tract were taken.

For the behavioral studies, animals were prepared for surgery as described above. Antisense delivery for the behavioral studies was accomplished through the use of chronically implanted bilateral cannulas implanted $1 \mathrm{~mm}$ above the injection site 1 week before the delivery of antisense to minimize surgical artifacts in the subsequent behavior. The cannulas were stereotactically situated at anteroposterior, $-3.8 \mathrm{~mm}$; mediolateral, \pm 2.0 or $\pm 2.5 \mathrm{~mm}$; and dorsoventral, -1.0 or $-1.5 \mathrm{~mm}$ and were sealed in place to the skull using dental acrylic. The second set of coordinates were chosen after the first set of animals to achieve better delivery of the antisense to the hippocampus. Animals were randomly assigned to one of three treatment groups, antisense-NR2B, scrambledNR2B, or vehicle (PBS), and the injections were delivered through an injection cannula that protruded $1 \mathrm{~mm}$ from the end of the implanted cannula the day before behavioral training began. After behavioral testing was completed, the animals were killed, and their brains were removed. The brains were frozen and sectioned through the coronal plane at $40 \mu \mathrm{m}$ on a sliding microtome. Every fourth section was stained with cresyl violet using standard procedures. Cannula sites were verified, and animals were excluded from the study if both cannulas were not placed within the CA1 region of the dorsal hippocampus or if evidence of an infection was noted at any point during the necropsy by an experimentor blinded to the treatment group of the rats.

Electrophysiology. Recording electrodes were made from finely drawn glass capillary tubes filled with artificial CSF (in mM: 124 sodium, 4 potassium, 1 magnesium chloride, 2.5 calcium chloride, 1 monobasic potassium phosphate, and 10 glucose) into which a silver wire was inserted. Stimulating electrodes were bipolar $100 \mu \mathrm{m}$ nichrome wire. All recordings were performed by stimulating the Schaeffer collateral fibers and recording in the dendritic layer for EPSPs and in the cell body layer for population spikes.

Because AMPA receptors contribute the bulk of the current for an EPSP, the EPSP slope and amplitude were considered the AMPA receptor response to stimulation. Varying stimulation intensity over the range of $1-10 \mathrm{~V}$ produced an AMPA input-output (I-O) curve. NMDA receptor responses were isolated by incubating hippocampal slices in 2 $\mu \mathrm{M}$ NBQX for $1 \mathrm{hr}$ without stimulation before measurement of the NMDA response. Stimulation intensity was varied to produce an NMDA I-O curve similar to the AMPA I-O curve.

HFS-induced LTP was produced with four trains of $1 \mathrm{sec}$ of $100 \mathrm{~Hz}$ stimulation $(150 \mu \mathrm{sec}$ pulse duration) separated from each other by 30 sec. Stimulation intensity was set at the voltage that elicited $50 \%$ of the maximal clean EPSP response. A minimum of a $30 \mathrm{~min}$ baseline response was collected before induction of LTP.

Nifedipine at a concentration of $25 \mu \mathrm{M}$ was used to inhibit postsynaptic voltage-gated calcium channels. 7-Chloro-kyurenic acid (7-CK) was used at $6 \mu \mathrm{M}$ to inhibit NMDA responses. Spermine was applied at $100 \mu \mathrm{M}$ to potentiate NMDA responses. All drugs were applied for at least $30 \mathrm{~min}$ before obtaining a baseline response.

\section{RESULTS}

We first explored the relationship between NMDA receptor expression and spatial learning using the Morris water maze in young (6 month) and aged (16-24 month) animals. As expected, an age-related deficit was evident when young and aged animals were compared by repeated measures ANOVA across days of the training trials (Fig. $1 A$ ) and on probe trials (Fig. 2A,C). Aged animals had significantly higher cumulative distance from platform (Gallagher et al., 1993) scores on days 3 and 4 (Figs. $1 A$, $2 A, C)$; this block of $2 \mathrm{~d}$ was chosen for further study, because performance during this block showed greater variability both across age groups and within the aged group. After training, the hippocampal protein expression levels of the NR1, NR2A, and NR2B subunits of the NMDA receptor, the GluR1 and GluR2 

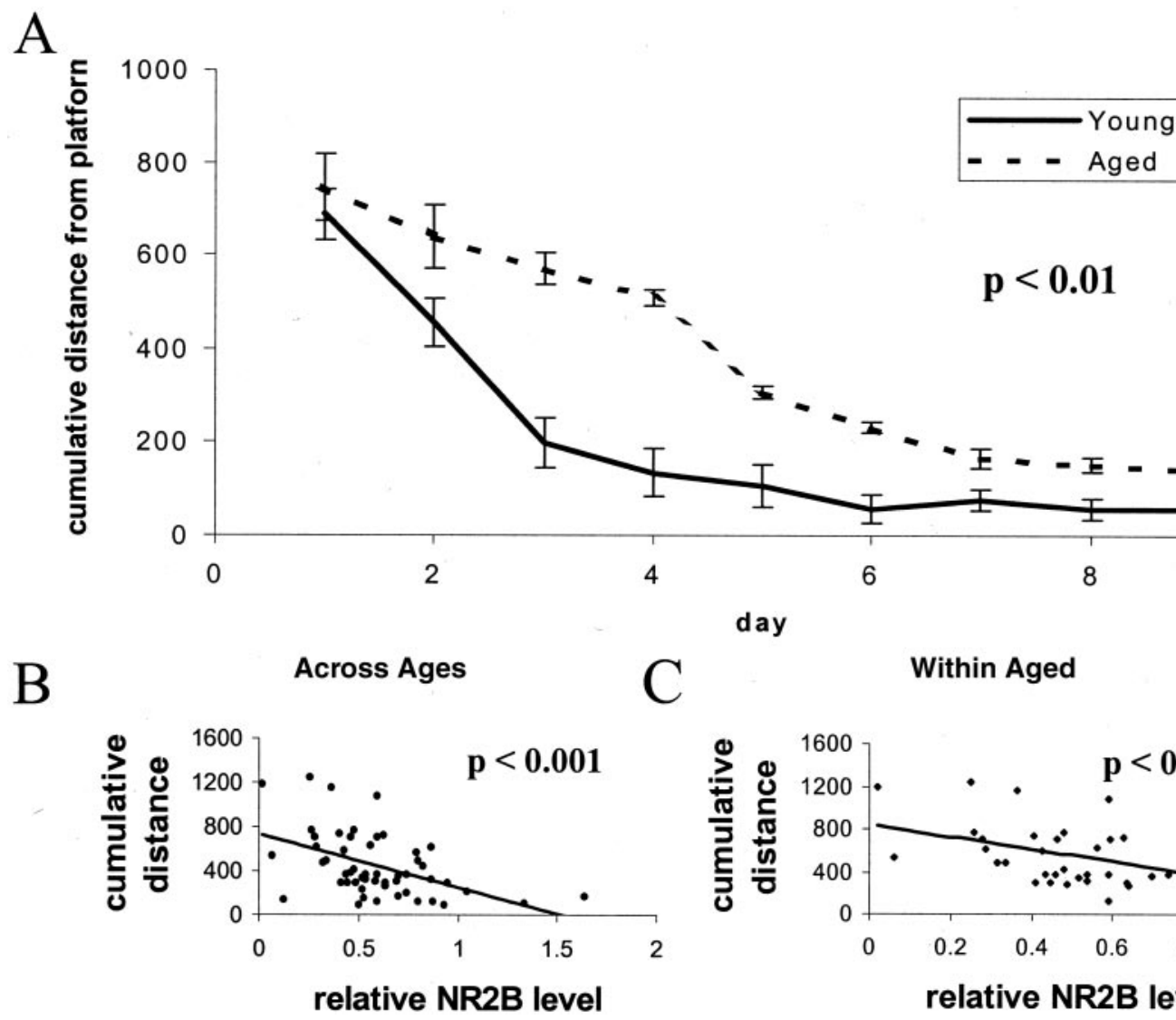

ay
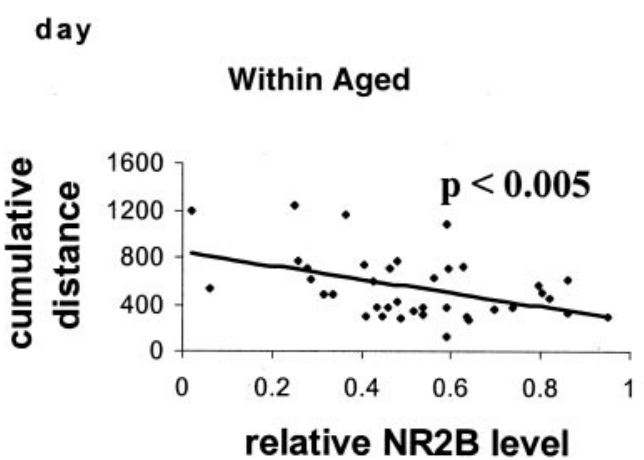

Figure 1. Spatial learning correlates with hippocampal expression of NR2B: training trials. $A$, Spatial learning, as assessed by three trials per day for $10 \mathrm{~d}$ in a Morris water maze hidden platform paradigm, reveals a significant age-related deficit in cumulative distance from platform (number of animals: aged, $n=8$ at 16 months, 24 at 22 months, and 8 at 23 months; young, $n=14$ at 6 months; $p=0.003$ by repeated measures ANOVA). Distance units shown are in a linear, calibrated arbitrary tracking unit. $B$, Regression analysis between performance in the Morris Water maze on days 3 and 4 and expression of the NR2B subunit reveals a significant association across animals in all age groups $\left(p=0.0003 ; R^{2}=0.23\right)$. Distance units shown are in a linear, calibrated arbitrary tracking unit. $C$, Regression analysis between performance in the Morris Water maze on days 3 and 4 and expression of the NR2B subunit reveals a significant association across animals in the aged group $\left(16,22\right.$, and 23 months; $\left.p=0.005 ; R^{2}=0.20\right)$. Distance units shown are in a linear, calibrated arbitrary tracking unit.

subunits of the AMPA receptor, and the synaptic marker protein synapsin were determined by Western blotting, as previously described (Eckles-Smith et al., 2000; Clayton and Browning, 2001)). We found, as previously reported (Eckles-Smith et al., 2000; Magnusson, 2000; Sonntag et al., 2000; Clayton and Browning, 2001), that there was an age-related decrease in NR1 and NR2B expression with no effect on NR2A, GluR1, GluR2, or synapsin expression (Fig. 3). Regression analysis was performed between scores for cumulative distance from the platform on days 3 and 4 and the average distance from the platform in probe trials on day 4, the days of greatest difference in performance, and receptor subunit expression. There was a significant correlation between levels of NR2B protein and behavioral performance across ages, suggesting that decreased expression of NR2B contributed to the difference in behavior between these groups (Figs. $1 B, 2 B)$. There was also a significant correlation within the aged animals, suggesting that differences in NR2B expression contributed to the differences in behavior among the aged rats as well (Figs. 1C, 2C). There were also significant correlations between NR2B expression and the distance from the platform and latency to the platform (data not shown). There were no correlations between expression of any of the other measured receptor subunits and the cumulative distance from the platform, the distance to the platform, or latency to the platform on days 3 and 4 (data not shown). No correlations were found between NR2B expression and performance in probe trials as measured by the number of platform crossings; we postulate that the lack of a broad dynamic range in this measure of probe trial performance complicates a correlational analysis. These data suggest that reduced NR2B expression could have a significant role in the behavioral deficits seen within the aged animal group.

We next tested whether we could ameliorate the age-related deficits in LTP by potentiating the NMDA receptor. We found that spermine $(100 \mu \mathrm{M})$ potentiated NMDA receptor function in slices from aged animals such that the responses were comparable with those seen in young animals (Fig. $4 A$ ). After such treatment, LTP in slices from aged animals was identical to that seen in slices from young animals (Fig. 4B). We then tested whether we could mimic age-related deficits in LTP in young animals by a partial blockade of the NMDA receptor. In slices from young animals, 7-CK $(6 \mu \mathrm{M})$ partially reduced NMDA receptor responses (Fig. $4 A$ ) to a level comparable with that seen in slices from aged animals. Importantly, this treatment completely blocked NMDAdependent LTP in young animals. All LTP experiments on aged animals were performed in the presence of $25 \mu \mathrm{M}$ nifedipine to block contributions from voltage-gated calcium channels, which 


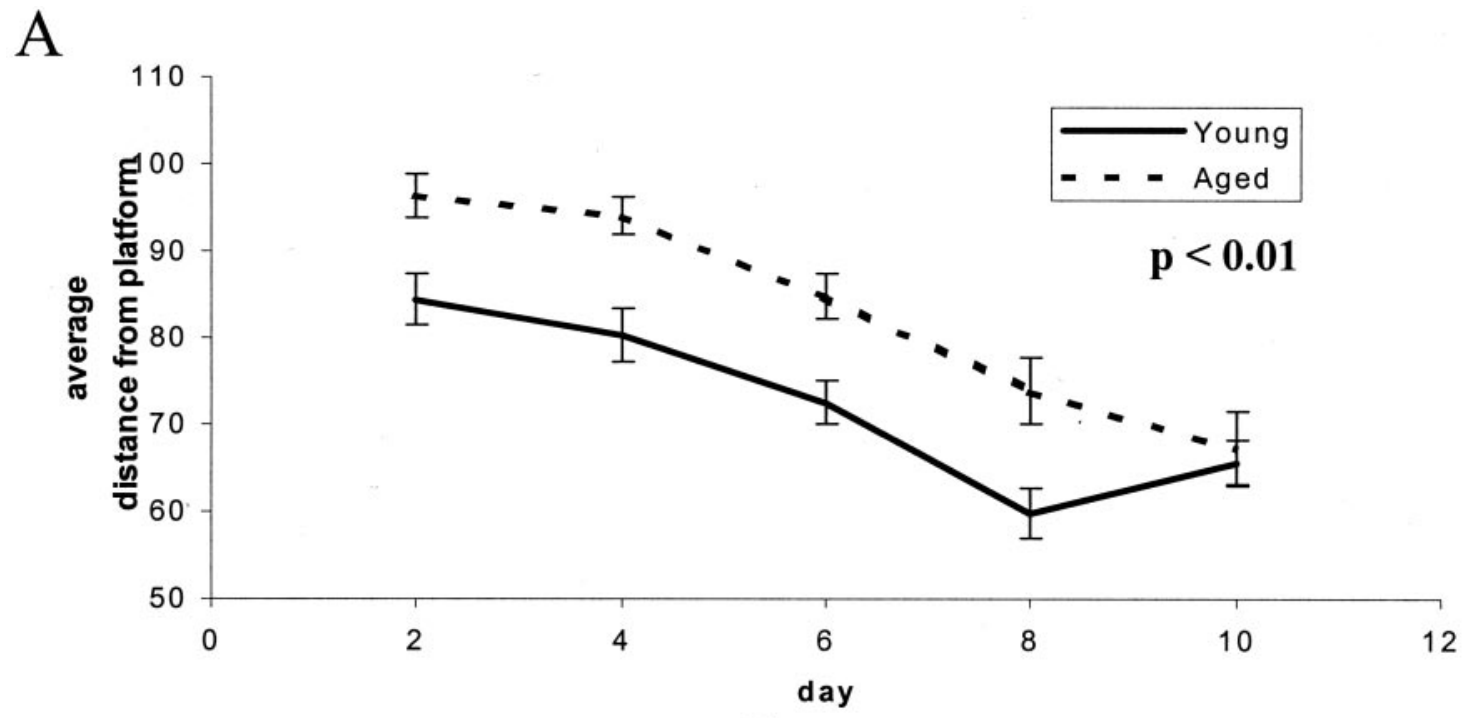

B

Across Ages

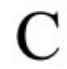

Within Aged
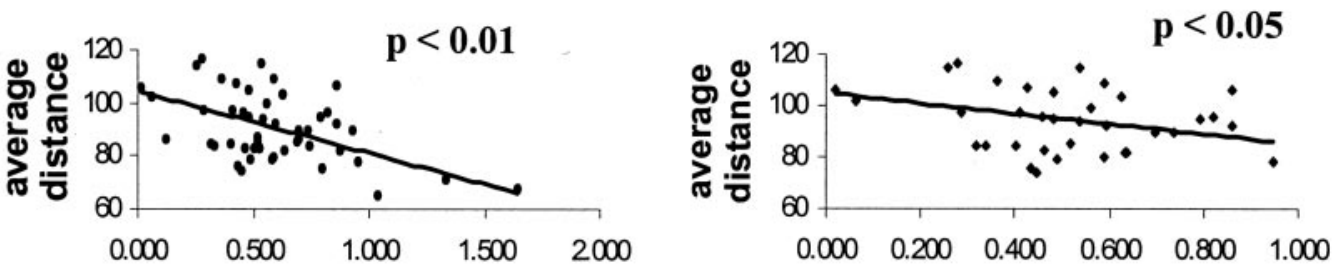

relative NR2B level

relative NR2B level

$\mathrm{D}$

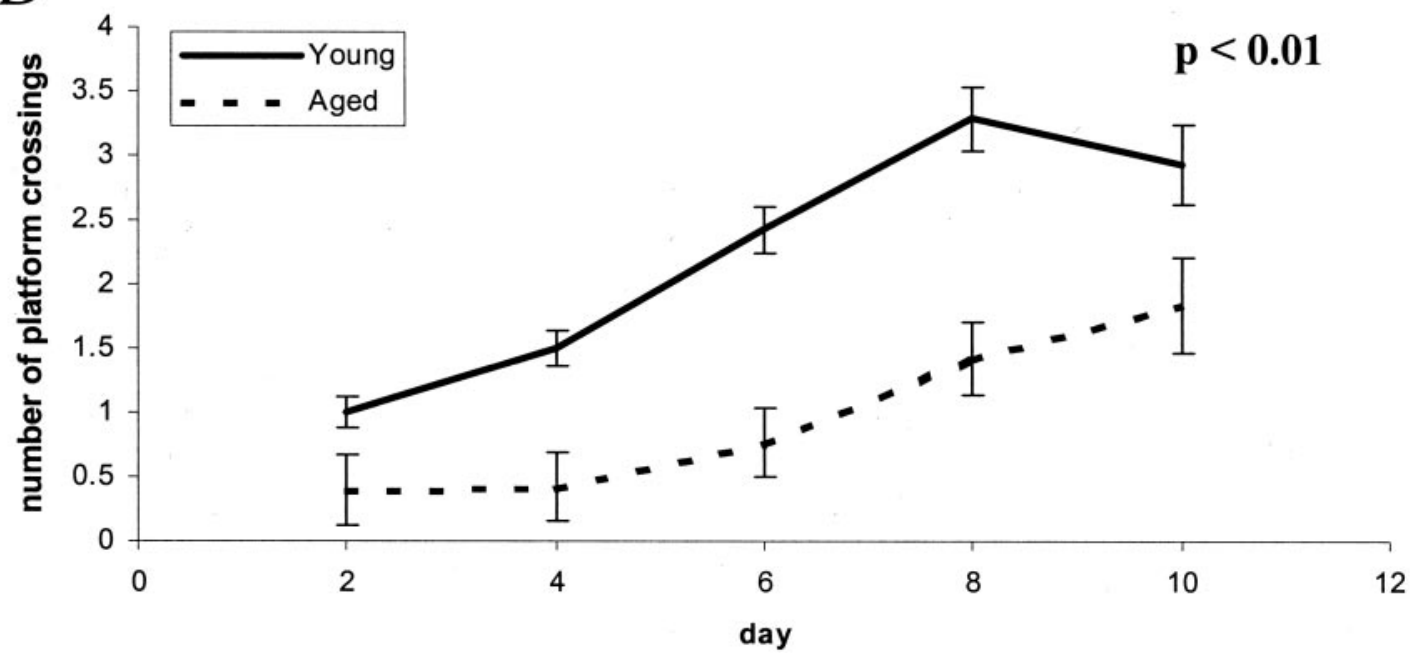

Figure 2. Spatial learning correlates with hippocampal expression of NR2B: probe trials. $A$, Spatial learning, as assessed by probe trials every other day during a $10 \mathrm{~d}$, three trial per day training paradigm in a Morris water maze with a hidden platform, reveals a significant age-related increase in the average distance from expected platform (number of animals: aged, $n=8$ at 16 months, 24 at 22 months, and 8 at 23 months; young, $n=14$ at 6 months; $p<$ 0.01 by repeated measures ANOVA). Distance units shown are in a linear, calibrated arbitrary tracking unit. $B$, Regression analysis between probe performance in the Morris Water maze on day 4 (average distance) and expression of the NR2B subunit reveals a significant association across animals in all age groups $\left(p<0.01 ; R^{2}=0.25\right)$. Distance units shown are in a linear, calibrated arbitrary tracking unit. $C$, Regression analysis between performance in the Morris Water maze on day 4 (average distance) and expression of the NR2B subunit reveals a significant association across animals in the aged group $\left(16,22\right.$, and 23 months; $\left.p<0.05 ; R^{2}=0.19\right)$. Distance units shown are in a linear, calibrated arbitrary tracking unit. $D$, Spatial learning, as assessed by probe trials every other day during a $10 \mathrm{~d}$, three trial per day training paradigm in a Morris water maze with a hidden platform, reveals a significant age-related deficit in the numbers of platform crossings (number of animals: aged, $n=8$ at 16 months, 24 at 22 months, and 8 at 23 months, young, $n=14$ at 6 months; $p<0.01$ by repeated measures ANOVA). Distance units shown are in a linear, calibrated arbitrary tracking unit. 


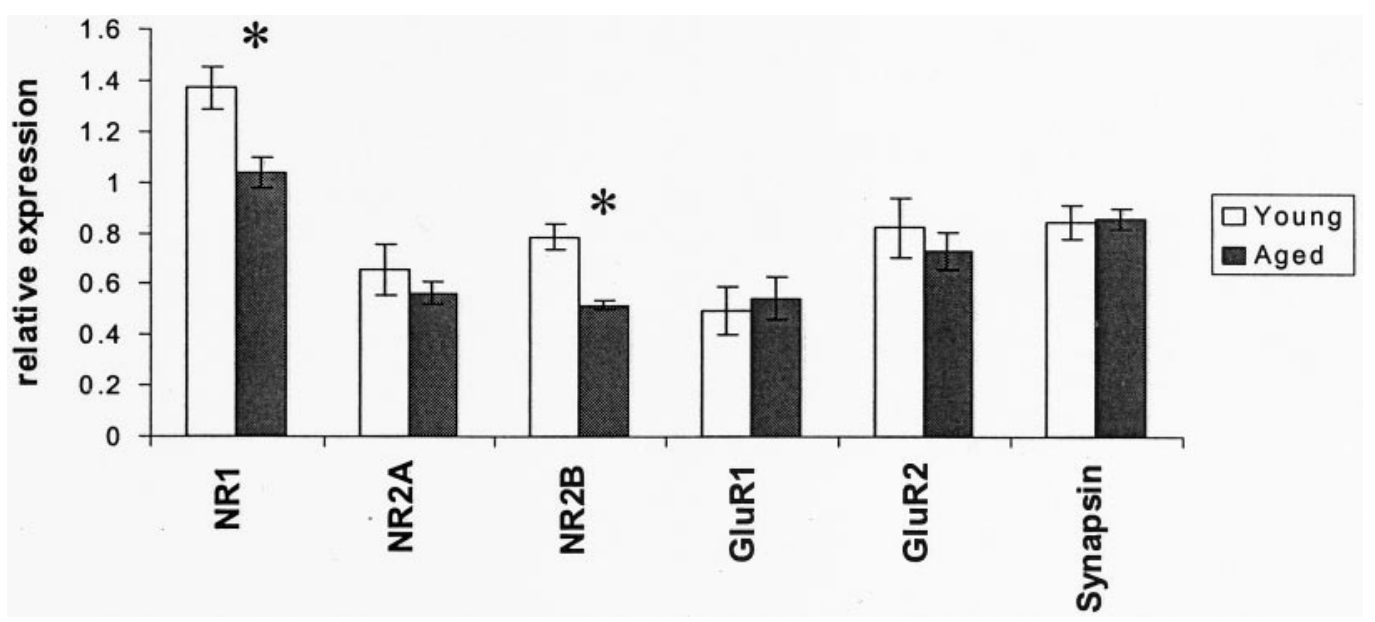

Figure 3. Age-related deficits in the expression of NMDA receptor subunits. Relative expression of NR2B protein between young and aged groups reveals a significant age-related decrease [37.5\% reduction aged/young; number of animals: $n=38 / 14 ; p=0.002$, ANOVA with Fisher's protected least significant difference (PLSD) post hoc test]. A significant age-related decrease in NR1 levels is also found (25.2\% reduction aged/young; number of animals: $n=38 / 14 ; p=0.01$, ANOVA with Fisher's PLSD post hoc test) that is not found in the relative expression of NR2A, GluR1, GluR2, or synapsin $(p=0.35 ; p=0.44 ; p=0.72 ; p=0.98$, respectively). Asterisks designate significant $(<0.05) p$ values.

have been shown to make a large contribution to the size of the EPSP in aged animals; thus, we sought to measure the amount of LTP that was elicitable solely through the activation of NMDA receptors (Cavus and Teyler, 1996; Izumi and Zorumski, 1998; Shankar et al., 1998; Morgan and Teyler, 1999).

To directly address the effect of an NR2B deficit, we used antisense oligonucleotides to knock down NR2B expression in young animals and to test whether this was sufficient to impair LTP and spatial learning. Antisense oligonucleotides were derived against the NR2B subunit and were specifically chosen not to cross-hybridize with any other known rat genes (including NR2A) with a mismatch of $>65 \%$. Scrambled antisense controls (in which the same base composition is maintained but the sequence is different) were also used to control for nonspecific phosphorothioate antisense effects. Stereotactic delivery of 10 nmol of antisense oligonucleotide to the hippocampus of young rats led to a time-dependent reduction (greatest decrease observed at $3 \mathrm{~d}, \sim 60 \%$ ) in NR2B protein (Fig. $5 A$ ). There was no change was in expression of other NMDA receptor subunits (NR1 and NR2A), in expression of AMPA receptor subunits (GluR1 and GluR2), or in expression of the synaptic marker synapsin (Fig. 5A). Injection of scrambled NR2B antisense had no effect on expression of any of the subunits that we measured (data not shown). Antisense treatment reduced NMDA receptor responses by $\sim 40 \%$ (Fig. $5 B$ ) and completely blocked NMDAdependent LTP (Fig. 5C). It has been proposed that NR2Bcontaining receptors might be confined primarily to extrasynaptic sites in cortical neurons (Stocca and Vicini, 1998). However, our data show that the NR2B subunit is a very important component of synaptic NMDA responses in the CA1 region of the hippocampus and that even a partial reduction in the expression of the NR2B subunit is sufficient to completely inhibit LTP.

To test the effect of reduced NR2B expression on behavior, antisense oligonucleotides were delivered bilaterally via cannulas to the hippocampi of young Fischer 344 rats. Spatial task performance was measured in the Morris water maze with four trials per day for $4 \mathrm{~d}$, starting the day after injections. This training regimen was chosen to match the time course of the antisenseinduced depression in NR2B protein levels. Antisense injection resulted in a significant impairment in spatial learning performance (Fig. $6 B$ ). This behavioral effect was most profound on the second day of training, which corresponds to the third day after injection, when the greatest suppression of NR2B protein occurred (Fig. 6A).

\section{DISCUSSION}

The data we present here indicate that the age-related deficit in the expression of NR2B is likely to have profound consequences for cognitive function. We show for the first time that there is a significant correlation between NR2B expression and performance in the Morris water maze both across ages (4-24 months) and within the aged animal group (16-24 months; no significant differences were noted between ages within this group). These data complement a report demonstrating that overexpression of the NR2B subunit leads to both enhanced LTP and enhanced performance on behavioral indices of learning and memory (Tang et al., 1999).

It is important to note that the pronounced decline in cognitive function that is associated with aging has been linked to a number of different perturbations in cellular and molecular processes that occur with age. Thus, growth factors, antioxidants, and numerous defects in signal transduction have all been implicated in agerelated behavioral deficits. (Williams et al., 1993; Backman et al., 1996; Yau et al., 1996; Lynch, 1998; Markowska et al., 1998; Bach et al., 1999; McGahon et al., 1999; Eckles-Smith et al., 2000). What remains to be elucidated is the sequence of molecular and cellular events that lead to these behavioral deficits. It is also critical to distinguish age-related alterations that, for example, play key roles in memory deficits from deficits that may reflect normal aging processes unrelated to memory formation. For example, we have previously shown that expression of the NR1 subunit of the NMDA receptor (NMDAR) is reduced in aged animals and that caloric restriction reversed this deficit in NR1 expression and ameliorated age-related deficits in LTP. However, we have not observed a correlation between the magnitude of this NR1 deficit and behavioral deficits; however, another recently published study suggests a link between NR1 levels in the CA3 


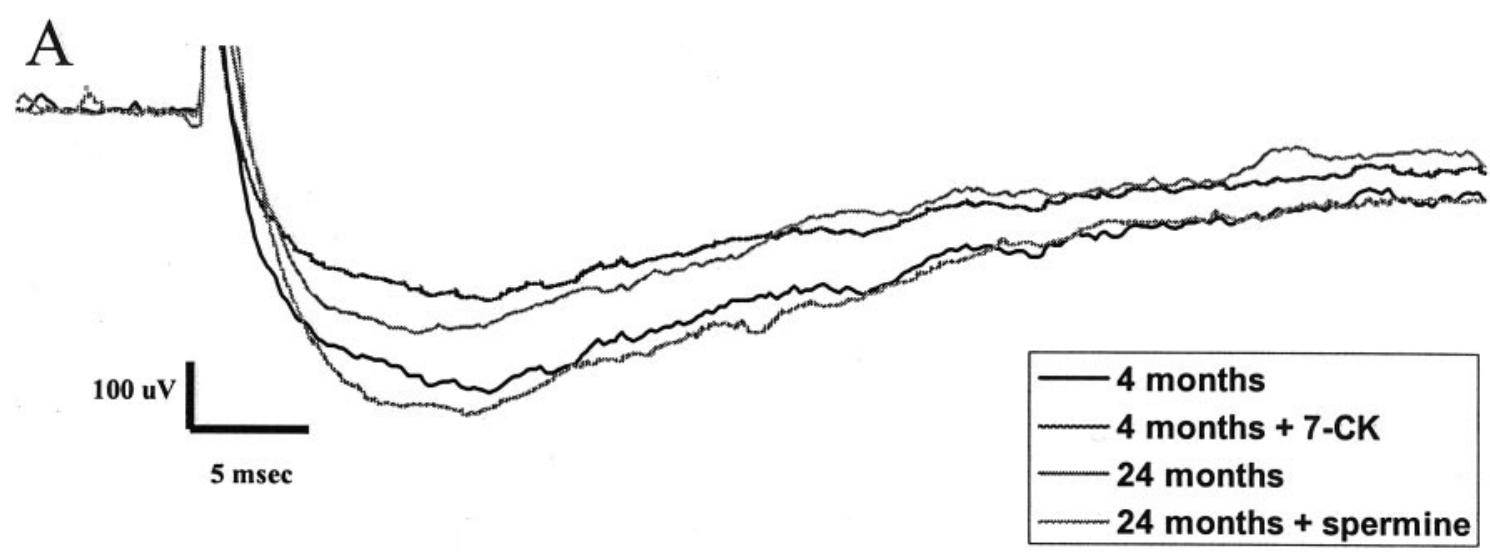

\section{$\mathrm{B}$}

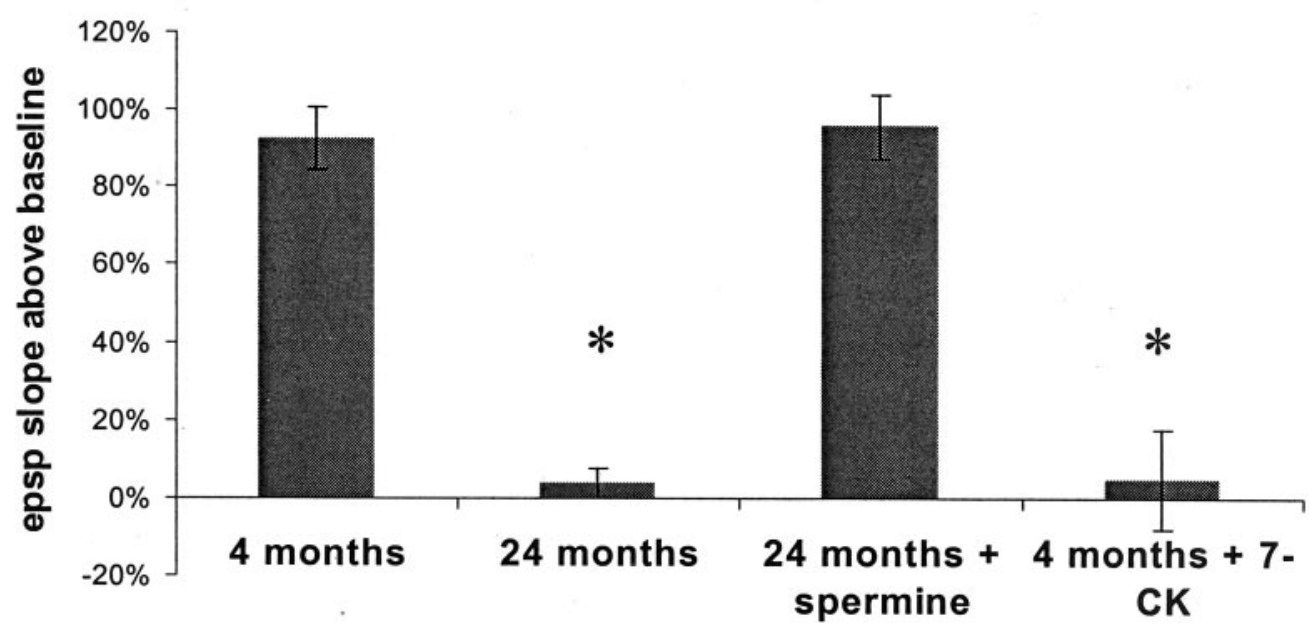

Figure 4. Age-related NMDA receptor functional deficits. $A$, Representative traces from pharmacologically isolated NMDA EPSPs recorded from Fischer 344 rats at 4 and 24 months of age revealing a deficit in aged responses (36.2\% reduction 24/4 months; number of animals: $n=6 ; p=0.02)$. This decline in the NMDA EPSP can be reproduced in young animals by treatment of the NMDA response with $6 \mu \mathrm{M} 7$-CK $(45.3 \%$ reduction treated/untreated; number of animals: $n=6 ; p=0.005)$ and can be ameliorated in aged animals by $100 \mu \mathrm{M}$ spermine (3.2\% reduction 24 month spermine/4 months; number of animals: $n=6 ; p=0.99$ ). Responses shown are at the same stimulus intensity at the midrange of our standard I-O response curves. $B$, HFS-induced LTP measured 30 min after induction in the presence of $10 \mu \mathrm{M}$ nifedipine reveals a significant age-dependent decline 24 months (94.8\% reduction 24/4 months, number of animals: $n=6 ; p=0.0008)$ that is reproduced in young animals by the addition of $6 \mu \mathrm{M} 7-\mathrm{CK}(92.4 \%$ reduction treated/untreated; number of animals: $n=6 ; p=0.003)$ and is ameliorated in aged animals by the addition of $100 \mu \mathrm{M}$ spermine $(103 \% 24$ month spermine/4 months; number of animals: $n=6 ; p=1)$. All statistics performed by ANOVA with Fisher's PLSD post hoc test. *Significance $(p<$ $0.05)$ compared with 4 month group.

region of the hippocampus and learning in aged animals (Adams et al., 2001). Thus, the age-related deficit in NR1 expression we have observed may not be causally linked to age-related deficits in behavior on the Morris water maze. Even when positive correlations between behavior and protein expression of the type we have observed for NR2B are found, numerous additional studies are still required to truly establish a link between expression changes and behavior. It is also possible that the age-related changes seen in NR2B expression represent a common end point through which multiple mechanisms of age-related degeneration converge.

We have used an antisense strategy to further explore the link between NR2B expression and LTP and behavior. We reasoned that if an age-related reduction in hippocampal NR2B expression is causally linked to age-related deficits, then we should be able to reproduce those deficits in young animals using antisense to acutely and selectively reduce NR2B expression. The data we have presented here show that we can produce a transitory and selective reduction of NR2B expression with antisense injection into the hippocampus. These injections significantly reduced NR2B expression and NMDAR responses. It also completely blocked induction of NMDAR-dependent LTP. Thus the NR2B subunit appears to play a key role in LTP in the CA1 region of young adult Fischer 344 rats. Importantly, NR2B antisense injection produced a significant impairment in spatial learning performance. Thus a reduction in NR2B expression is sufficient to significantly impair behavior on the Morris water maze.

We have also demonstrated that we can at least partially ameliorate the age-related deficits in LTP by using spermine to potentiate the NMDAR receptor. However, spermine affects a number of other signaling pathways in addition to the NMDAR. Moreover, it is not practical to explore the effects of spermine on 


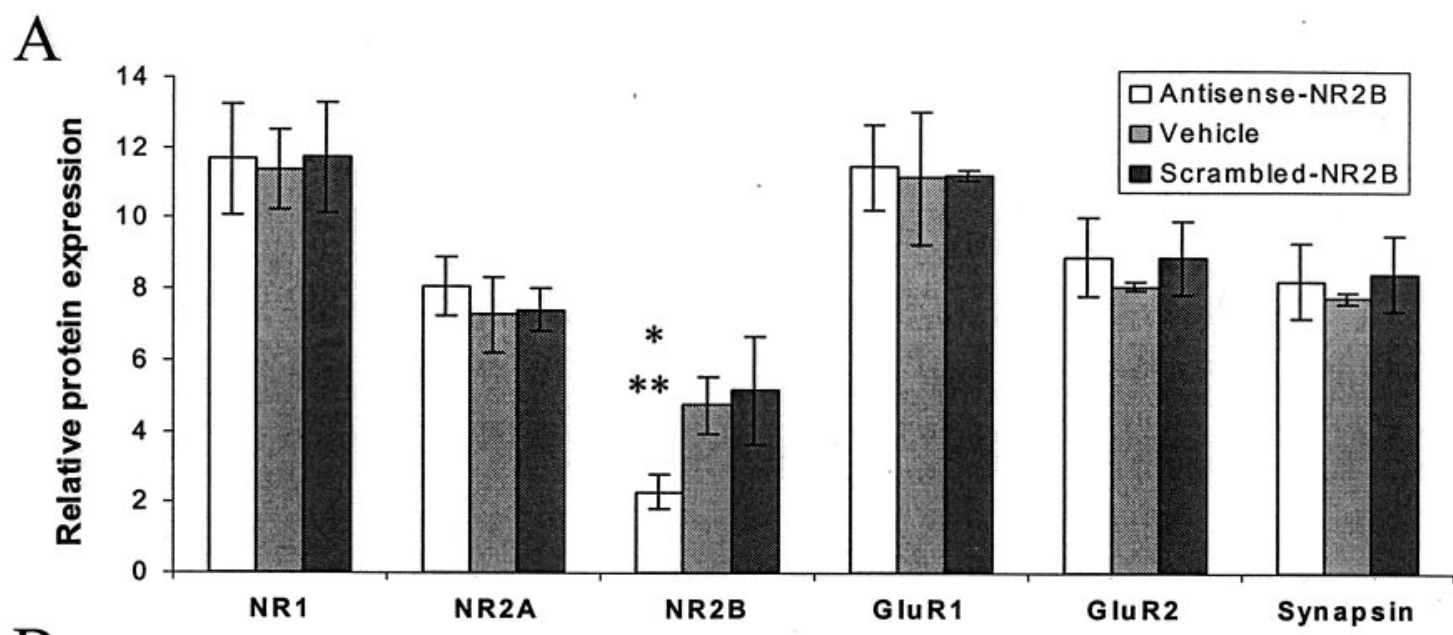

B
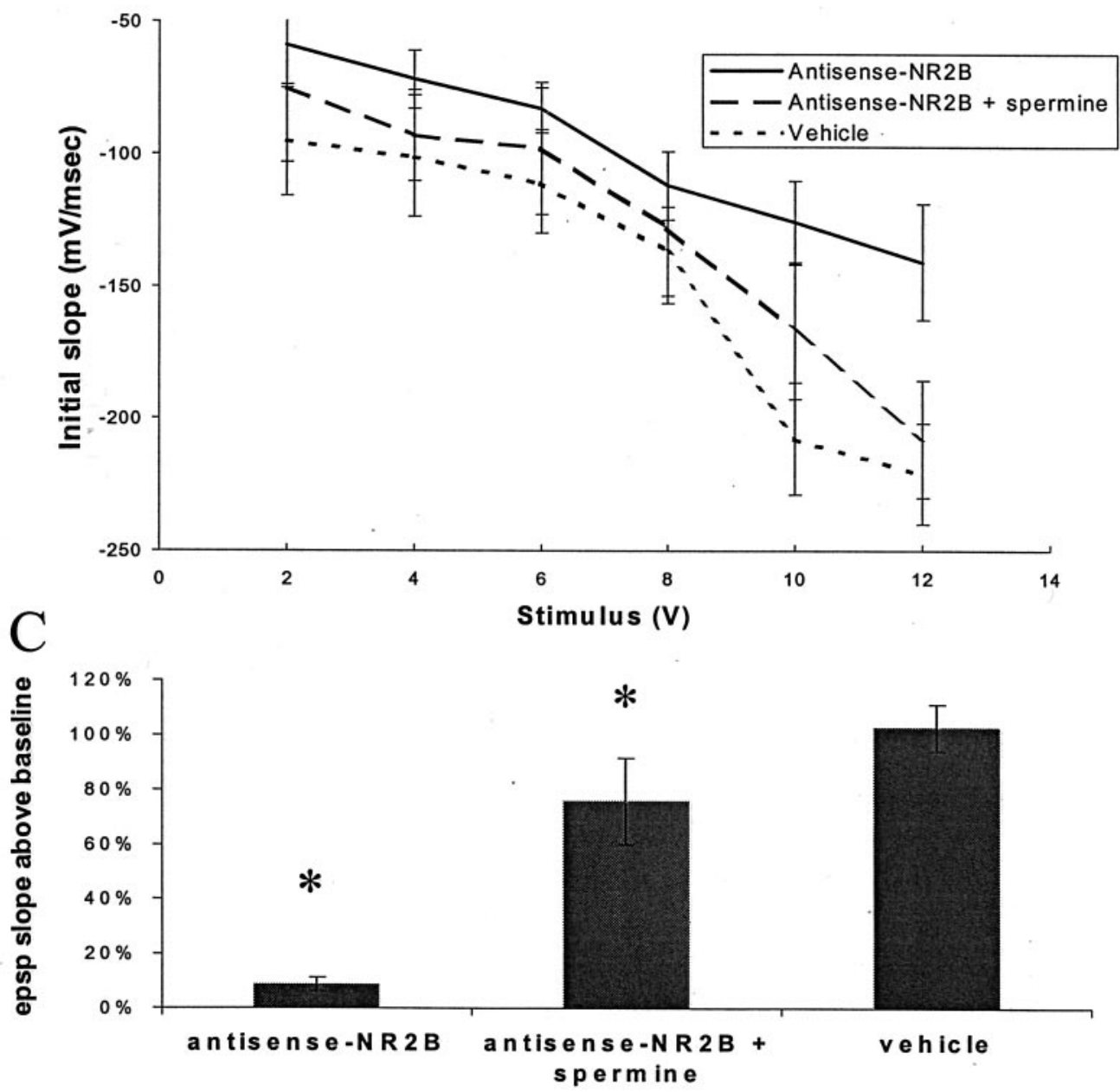

Figure 5. Effect of antisense-NR2B treatment. $A$, Injection of antisense-NR2B oligonucleotides leads to a selective hippocampal loss of NR2B protein at $3 \mathrm{~d}$ after injection (63\% reduction antisense/scrambled; number of animals: $n=16 / 8 ; p=0.002 ; 59 \%$ reduction antisense/vehicle; number of animals: $n=16 / 16 ; p=0.001$ ). No significant changes were seen in the expression of NR1, NR2A, GluR1, GluR2, or synapsin (all $p>0.50$, statistics by ANOVA with Fisher's PLSD post hoc test within group, Bonferroni adjusted between groups). *Significance to vehicle treatment; ***ignificance to scrambled treatment. $B$, NMDA receptor responses are diminished in slices from antisense-NR2B-treated animals relative to control (number of animals: $n=6$; $p=0.04$ ), and this difference can be ameliorated by treatment with $100 \mu \mathrm{M}$ spermine (number of animals: $n=6 ; p=0.25$, statistics by repeated measures ANOVA). $C$, Antisense-NR2B treatment leads to a decrease in the amount of HFS-induced LTP measured 30 min after induction (93.2\% reduction antisense/vehicle; $n=6 ; p=0.003)$, which can be ameliorated by $100 \mu \mathrm{M}$ spermine ( $70.8 \%$ reduction antisense/antisense and spermine; number of animals: $n=6 ; p=0.008$, statistics by ANOVA with Fisher's PLSD post hoc test). *Significance to antisense treatment. 


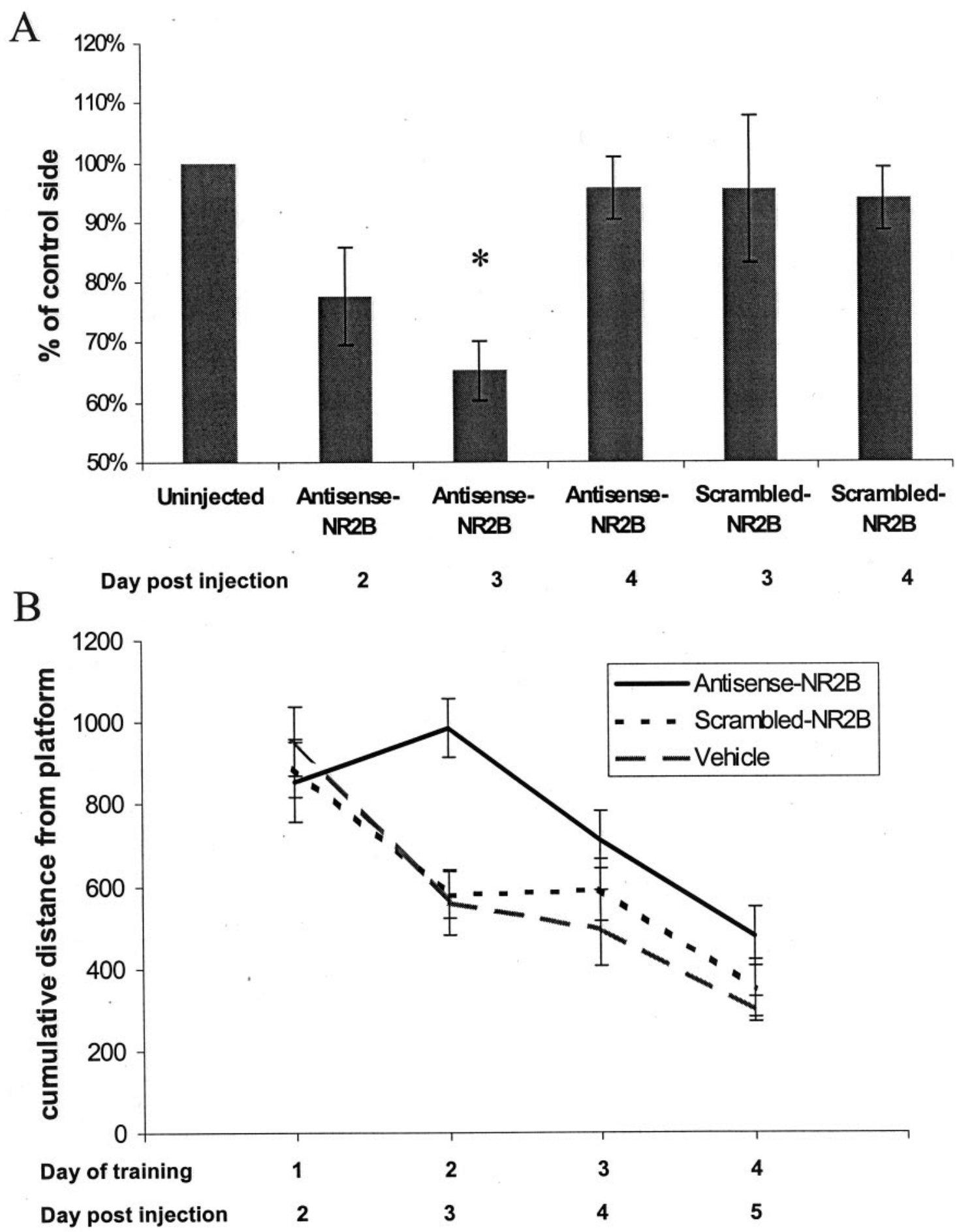

Figure 6. Time dependent antisense-NR2B effects. $A$, Antisense-NR2B injection leads to a time-dependent decrease in the amount of hippocampal NR2B protein that is most significant on day 3 after injection (35\% reduction antisense-NR2B/vehicle; number of animals: $n=16 ; p=0.002$ ). Scrambled-NR2B controls do not show a significant decrease in the amount of NR2B protein on either day 3 or day 4 . B, Spatial learning performance, assessed by four trials per day for $4 \mathrm{~d}$ in a Morris water maze hidden platform task, shows a significant time-dependent difference between antisense-NR2B-treated animals and both vehicle- and scrambled-NR2B-treated controls $(p=0.058$ by repeated measures ANOVA) that is most pronounced on day 2 of training, which corresponds to day 3 after injection ( $p=0.02$, antisense-NR2B/scrambled-NR2B; $p=0.035$, antisense-NR2B/ vehicle, by ANOVA with Fisher's PLSD post hoc test). Distance units shown are in a linear, calibrated arbitrary tracking unit.

behavior. What is clearly needed is an intervention that can selectively enhance NR2B expression in aged animals. The mechanism underlying the age-related reduction in NR2B expression is unknown; however, several possible mechanisms can be pro- posed. Aged animals are thought to have elevated intracellular calcium levels attributable to alterations in calcium homeostasis and elevated voltage-gated calcium channel activity (Campbell et al., 1996; Thibault et al., 1998), and activity-dependent increases 
in calcium lead to a selective downregulation of NR2B (Audinat et al., 1994; Vallano et al., 1996). Thus the reduced NR2B expression in aged animals could be a consequence of elevated voltage-gated calcium channel activity. Defects in protein kinase A (PKA) signaling have also been implicated in aging; activators of PKA signaling ameliorate or reverse age-related deficits in behavior and LTP (Gould and Bickford, 1997; Bach et al., 1999). The promoter region of the NR2B gene contains a cAMP response element-binding protein (CREB) consensus sequence (Myers et al., 1999); thus, decreased activity of PKA could lead via decreased activation of CREB to a reduction in expression of NR2B.

In summary, the data we have presented here indicate that NR2B plays an important role in NMDA-dependent LTP in young animals. Moreover, these data provide strong support for the hypothesis that a deficit in NR2B expression may play a critically important role in age-related cognitive decline.

\section{REFERENCES}

Adams MM, Smith TD, Moga D, Gallagher M, Wang Y, Wolfe BB, Rapp PR, Morrison JH (2001) Hippocampal dependent learning ability correlates with $N$-methyl-D-aspartate (NMDA) receptor levels in CA3 neurons of young and aged rats. J Comp Neurol 432:230-243.

Audinat E, Lambolez B, Rossier J, Crepel F (1994) Activity-dependent regulation of $N$-methyl-D-aspartate receptor subunit expression in rat cerebellar granule cells. Eur J Neurosci 6:1792-1800.

Audinat E, Lambolez B, Rossier J (1996) Functional and molecular analysis of glutamate-gated channels by patch-clamp and RT-PCR at the single cell level. Neurochem Int 28:119-136.

Bach ME, Barad M, Son H, Zhuo M, Lu YF, Shih R, Mansuy I, Hawkins RD, Kandel ER (1999) Age-related defects in spatial memory are correlated with defects in the late phase of hippocampal long-term potentiation in vitro and are attenuated by drugs that enhance the cAMP signaling pathway. Proc Natl Acad Sci USA 96:5280-5285.

Backman C, Rose GM, Hoffer BJ, Henry MA, Bartus RT, Friden P, Granholm AC (1996) Systemic administration of a nerve growth factor conjugate reverses age-related cognitive dysfunction and prevents cholinergic neuron atrophy. J Neurosci 16:5437-5442.

Barnes CA (1979) Memory deficits associated with senescence: a neurophysiological and behavioral study in the rat. J Comp Physiol Psychol 93:74-104.

Barnes CA, Nadel L, Honig WK (1980) Spatial memory deficit in senescent rats. Can J Psychol 34:29-39.

Barnes CA, Rao G, Shen J (1997) Age-related decrease in the $N$-methylD-aspartateR-mediated excitatory postsynaptic potential in hippocampal region CA1. Neurobiol Aging 18:445-452.

Brimecombe JC, Boeckman FA, Aizenman E (1997) Functional consequences of NR2 subunit composition in single recombinant $N$-methylD-aspartate receptors. Proc Natl Acad Sci USA 94:11019-11024.

Campbell LW, Hao SY, Thibault O, Blalock EM, Landfield PW (1996) Aging changes in voltage-gated calcium currents in hippocampal CA1 neurons. J Neurosci 16:6286-6295.

Cavus I, Teyler T (1996) Two forms of long-term potentiation in area CA1 activate different signal transduction cascades. J Neurophysiol 76:3038-3047.

Clayton DA, Browning MD (2001) Deficits in the expression of the NR2B subunit in the hippocampus of aged Fisher 344 rats. Neurobiol Aging 22:165-168.

Costenla AR, de Mendonca A, Ribeiro JA (1999) Adenosine modulates synaptic plasticity in hippocampal slices from aged rats. Brain Res 851:228-234.

deToledo-Morrell L, Geinisman Y, Morrell F (1988) Age-dependent alterations in hippocampal synaptic plasticity: relation to memory disorders. Neurobiol Aging 9:581-590.

Eckles-Smith K, Clayton D, Bickford P, Browning MD (2000) Caloric restriction prevents age-related deficits in LTP and in NMDA receptor expression. Brain Res Mol Brain Res 78:154-162.

Flint AC, Maisch US, Weishaupt JH, Kriegstein AR, Monyer H (1997) NR2A subunit expression shortens NMDA receptor synaptic currents in developing neocortex. J Neurosci 17:2469-2476.

Gallagher M, Burwell R, Burchinal M (1993) Severity of spatial learning impairment in aging: development of a learning index for performance in the Morris water maze. Behav Neurosci 107:618-626.

Gould TJ, Bickford PC (1997) Age-related deficits in the cerebellar beta adrenergic signal transduction cascade in Fischer 344 rats. J Pharmacol Exp Ther 281:965-971.

Granger R, Deadwyler S, Davis M, Moskovitz B, Kessler M, Rogers G, Lynch G (1996) Facilitation of glutamate receptors reverses an ageassociated memory impairment in rats. Synapse 22:332-337.

Huber KM, Mauk MD, Kelly PT (1995) Distinct LTP induction mechanisms: contribution of NMDA receptors and voltage-dependent calcium channels. J Neurophysiol 73:270-279.

Izumi Y, Zorumski CF (1998) LTP in CA1 of the adult rat hippocampus and voltage-activated calcium channels. NeuroReport 9:3689-3691.

Kuehl-Kovarik MC, Magnusson KR, Premkumar LS, Partin KM (2000) Electrophysiological analysis of NMDA receptor subunit changes in the aging mouse cortex. Mech Aging Dev 115:39-59.

Lanahan A, Lyford G, Stevenson GS, Worley PF, Barnes CA (1997) Selective alteration of long-term potentiation-induced transcriptional response in hippocampus of aged, memory-impaired rats. J Neurosci 17:2876-2885.

Landfield PW, Lynch G (1977) Impaired monosynaptic potentiation in in vitro hippocampal slices from aged, memory-deficient rats. J Gerontol 32:523-533.

Landfield PW, McGaugh JL, Lynch G (1978) Impaired synaptic potentiation processes in the hippocampus of aged, memory-deficient rats. Brain Res 150:85-101.

Lynch MA (1998) Age-related impairment in long-term potentiation in hippocampus: a role for the cytokine, interleukin-1 beta? Prog Neurobiol 56:571-589.

Magnusson KR (2000) Declines in mRNA expression of different subunits may account for differential effects of aging on agonist and antagonist binding to the NMDA receptor. J Neurosci 20:1666-1674.

Markowska AL, Mooney M, Sonntag WE (1998) Insulin-like growth factor-1 ameliorates age-related behavioral deficits. Neuroscience 87:559-569.

McGahon BM, Murray CA, Horrobin DF, Lynch MA (1999) Agerelated changes in oxidative mechanisms and LTP are reversed by dietary manipulation. Neurobiol Aging 20:643-653.

Meguro H, Mori H, Araki K, Kushiya E, Kutsuwada T, Yamazaki M, Kumanishi T, Arakawa M, Sakimura K, Mishina M (1992) Functional characterization of a heteromeric NMDA receptor channel expressed from cloned cDNAs. Nature 357:70-74.

Moore CI, Browning MD, Rose GM (1993) Hippocampal plasticity induced by primed burst, but not long-term potentiation, stimulation is impaired in area CA1 of aged Fischer 344 rats. Hippocampus 3:57-66.

Morgan SL, Teyler TJ (1999) VDCCs and NMDARs underlie two forms of LTP in CA1 hippocampus in vivo. J Neurophysiol 82:736-740.

Myers SJ, Dingledine R, Borges K (1999) Genetic regulation of glutamate receptor ion channels. Annu Rev Pharmacol Toxicol 39:221-241.

Nayak A, Zastrow DJ, Lickteig R, Zahniser NR, Browning MD (1998) Maintenance of late-phase LTP is accompanied by PKA-dependent increase in AMPA receptor synthesis. Nature 394:680-683.

Rumbaugh G, Vicini S (1999) Distinct synaptic and extrasynaptic NMDA receptors in developing cerebellar granule neurons. J Neurosci 19:10603-10610.

Shankar S, Teyler TJ, Robbins N (1998) Aging differentially alters forms of long-term potentiation in rat hippocampal area CA1. J Neurophysiol 79:334-341.

Sonntag WE, Bennett SA, Khan AS, Thornton PL, Xu X, Ingram RL, Brunso-Bechtold JK (2000) Age and insulin-like growth factor-1 modulate $N$-methyl-D-aspartate receptor subtype expression in rats. Brain Res Bull 51:331-338.

Sprengel R, Suchanek B, Amico C, Brusa R, Burnashev N, Rozov A, Hvalby O, Jensen V, Paulsen O, Andersen P, Kim JJ, Thompson RF, Sun W, Webster LC, Grant SG, Eilers J, Konnerth A, Li J, McNamara JO, Seeburg PH (1998) Importance of the intracellular domain of NR2 subunits for NMDA receptor function in vivo. Cell 92:279-289.

Stocca G, Vicini S (1998) Increased contribution of NR2A subunit to synaptic NMDA receptors in developing rat cortical neurons. J Physiol (Lond) 507:13-24.

Tang YP, Shimizu E, Dube GR, Rampon C, Kerchner GA, Zhuo M, Liu G, Tsien JZ (1999) Genetic enhancement of learning and memory in mice. Nature 401:63-69.

Thibault O, Porter NM, Chen KC, Blalock EM, Kaminker PG, Clodfelter GV, Brewer LD, Landfield PW (1998) Calcium dysregulation in neuronal aging and Alzheimer's disease: history and new directions. Cell Calcium 24:417-433.

Tovar KR, Westbrook GL (1999) The incorporation of NMDA receptors with a distinct subunit composition at nascent hippocampal synapses in vitro. J Neurosci 19:4180-4188.

Tovar KR, Sprouffske K, Westbrook GL (2000) Fast NMDA receptormediated synaptic currents in neurons from mice lacking the epsilon2 (NR2B) subunit. J Neurophysiol 83:616-620. 
Vallano ML (1998) Developmental aspects of NMDA receptor function. Crit Rev Neurobiol 12:177-204.

Vallano ML, Lambolez B, Audinat E, Rossier J (1996) Neuronal activity differentially regulates NMDA receptor subunit expression in cerebellar granule cells. J Neurosci 16:631-639.

Ward MT, Oler JA, Markus EJ (1999a) Hippocampal dysfunction during aging I: deficits in memory consolidation. Neurobiol Aging $20: 363-372$.

Ward MT, Stoelzel CR, Markus EJ (1999b) Hippocampal dysfunction during aging II: deficits on the radial-arm maze. Neurobiol Aging 20:373-380.

Williams JH, Li YG, Nayak A, Errington ML, Murphy KP, Bliss TV
(1993) The suppression of long-term potentiation in rat hippocampus by inhibitors of nitric oxide synthase is temperature and age dependent. Neuron 11:877-884.

Yau JL, Olsson T, Morris RG, Noble J, Seckl JR (1996) Decreased NGFI-A gene expression in the hippocampus of cognitively impaired aged rats. Brain Res Mol Brain Res 42:354-357.

Zhao HM, Wenthold RJ, Petralia RS (1998) Glutamate receptor targeting to synaptic populations on Purkinje cells is developmentally regulated. J Neurosci 18:5517-5528.

Zhong J, Carrozza DP, Williams K, Pritchett DB, Molinoff PB (1995) Expression of mRNAs encoding subunits of the NMDA receptor in developing rat brain. J Neurochem 64:531-539. 